Cite as: Akonda MH, Stefanova M, Potluri P, Shah DU. Journal of Composite Materials. 2017. DOI: $10.1177 / 0021998316672091$

\title{
Mechanical properties of recycled carbon fibre/PET thermoplastic tape composites
}

\author{
M.H Akonda ${ }^{*}, 1$, M. Stefanova ${ }^{2}$, P. Potluri², D. U. Shah ${ }^{3}$ \\ ${ }^{1}$ Tilsatec Advanced Materials, Wakefield, UK. \\ 2, School of Materials, University of Manchester, UK \\ ${ }^{3}$ Centre for Natural Material Innovation, Dept. of Architecture, University of Cambridge, UK
}

\begin{abstract}
The increasing use of high-value carbon fibre in composites is linked with increasing waste generation: from dry fibre and prepreg offcuts during manufacturing to end-of-life parts. In this work, a novel thermoplastic tape was produced from 60 wt.\% manufacturing waste carbon fibres (60 mm long) and $40 \mathrm{wt}$.\% polyester (PET) fibres using a thermal consolidation technique. The thin $(0.2 \mathrm{~mm})$ and narrow (20mm wide) tapes were then used to fabricate laminated composite panels in two 0/90 tape architectures: cross-ply and woven ply. Various mechanical properties, including tensile, flexural, compression, and impact, were evaluated. It was found that cross-ply performed better than woven ply laminates, with failure in the latter materials typically initiating at the tape interlacement points.
\end{abstract}

\section{Keywords}

A: Tape, A: Thermoplastic resin, B: Delamination , D: Mechanical testing, E: Prepreg

*Corresponding Author: M. Akonda

m.akonda@tilsatec.com , Tel: +44 (0)1924 375742, Fax: +44 (0)1924 376204 


\section{Introduction}

The recycled carbon fibres used in this study were generated as manufacturing waste, as offcuts of virgin carbon fibre tows from various textile manufacturing processes such as weaving and multi-axial fabric production. Currently, these dry offcuts are treated as landfill waste. As the global production volume of carbon fibre reinforced plastics is growing at a substantial rate - from 46,000 tonnes in 2011 to 140,000 tonnes in 2020 [1-3] - a significant level (around 15\%) of off-cut tows (30-60 mm in length) will be generated in various carbon fibre reinforcement products manufacturing processes. However, as these are discontinuous lengths of the virgin material, they may still find applications in high-value composite parts. Doing so will not only reduce landfill waste, it will also eliminate the associated cost of disposal through landfilling and rather generate revenue by utilising the material. Therefore, new technology is desirable to re-use these waste off-cuts in composites.

Existing work $[4,5]$ has shown that waste off-cuts can be converted into yarns. The blends of chopped carbon fibre $(50 \mathrm{~mm})$ and polypropylene staple fibres $(60 \mathrm{~mm})$ were produced using a modified carding process to obtain a continuous sliver (continuous form of bundle of fibres), which was then subsequently drafted to convert into a spun yarn. The composites were fabricated from the recycled carbon fibre and polypropylene blended yarns. Although, the studies show that the final composites provide lower mechanical properties.

In general, carbon fibre reinforced thermoplastics offer substantial advantages over thermoset ones, such as higher toughness of the matrix and higher impact resistance of the composite [6]. Although, the manufacturing cycle of thermoplastic composite consists of melting the matrix for good fibre impregnation, and subsequent shaping and consolidation by cooling of the composite part, the overall cycle times required are significantly shorter than for thermoset composites. In addition, unlike thermoset prepregs, thermoplastic 'prepreg' tapes can be stored at ambient temperature indefinitely, thus being cost effective [7]. Consequently, 
thermoplastic tapes are becoming of increasing interest for advanced composites manufacture [6-8]. Moreover, with increasing concern for worker health and safety, and environmental issues, thermoplastics offer some respite; for example, unlike thermoset processing, in thermoplastic processing there are no solvents that would be off-gassed upon heating of the polymer, and there are no cure mechanisms that release volatile organic compounds as byproducts.

Many techniques have been developed to use carbon fibres of various lengths in thermoplastic resin systems. Milled fibres (1-100 $\mu \mathrm{m}$ in length) and short fibres (3-6mm in length) can be compounded with thermoplastic matrices like polyamide and polyetheretherketone, and then injection or compression moulded into small-to-medium sized, complex-shaped parts [9-10]. At the other end of the spectrum, continuous fibre thermoplastics are made from endless carbon fibres, which may be extruded with the thermoplastic matrix or blended using a commingling technique. These are then cut to asrequired lengths, yielding better mechanical properties than would be achieved by the use of shorter fibres [11].

Matrix impregnated, pre-consolidated composite prepregs are also used as they can be reconsolidated or stamped within minutes. Therefore, pre-consolidated thermoplastic composite prepregs have become more popular in recent years for high volume composite manufacturing. Hot-melt resin impregnation processes have been developed to obtain such pre-consolidated composite prepregs [12].

Currently, all thermoplastic composite prepegs of carbon fibres available in the market are produced from continuous, virgin carbon fibres. The virgin carbon fibre tows are expensive (20-60 £/kg) and the production process also adds further cost to pre-consolidated prepregs [11]. The high cost of the prepregs has limited their application in many sectors such as automotive and sports, where price of the end-products is a critical issue [6-8] for 
manufacturers. The composite industry demands low-cost pre-consolidated composite prepregs that can be used in stamp-forming and equivalent rapid production processes [13]. To keep the materials cost down, using waste, recycled or reclaimed, rather than virgin, carbon fibres is attractive. Furthermore, the re-use of waste carbon fibres in high-value materials facilitates current efforts to solve end-of-life and disposal issues of carbon fibre composites, and thermoset composites in general [14].

In this paper, a novel thermoplastic pre-consolidated, unidirectional tape from long (60 mm) waste carbon fibre and polyester (polyethylene terephthalate, PET) fibre is described, which can used in rapid production processes. This tape is processed to form woven architectures, and the dry prepreg is then moulded to form thermoplastic composites with good mechanical properties, higher than that of glass fibre composites.

\section{Materials}

In this proof-of-concept work, carbon fibres (T700) were sourced from Sigmatex UK in a staple form of $60 \mathrm{~mm}$ mean length. The polyester (polyethylene terephthalate, PET) fibres used were of $60 \mathrm{~mm}$ mean length, 6.7 dtex fineness (mass in grams of 10,000 meters of filaments) (ca. $28 \mu \mathrm{m}$ diameter) and 10-12 crimp/inch. The PET fibres were sourced from James Robinson Fibres Ltd. (UK). All materials were used as-obtained.

\section{Experimental work}

\subsection{Characterisation of waste carbon fibres and PET fibres}

Single fibre tensile tests on the carbon fibres were carried out in accordance with ISO 11566:1996. The load-extension curves obtained are shown in Figure 1a. Figure 1b displays load-extension curves of PET fibres. Unfilled PET plaques (200mm x 200mm x 2mm) were made from $100 \%$ PET fibres by hot-press moulding at $280{ }^{\circ} \mathrm{C}$ for $15 \mathrm{~min}$ and $3 \mathrm{MPa}$ 
pressure. The tensile and flexural properties of the unfilled PET plaques were measured in accordance with ISO 527-1:2012 and ISO 178:2003, respectively.

\subsection{Intermingling of fibres and tape production}

The staple carbon fibres were mixed with staple PET fibres in 60:40 weight ratios and continuous slivers were produced by using a modified carding process (see Figure 2a-c). Wide tapes (180mm width, $150 \mathrm{~g} / \mathrm{m}^{2}$ ) were produced by a thermal consolidation technique, as shown in Figure 2d-f, where the slivers (ten slivers) were assembled in parrallel and passed through a heating unit at $240{ }^{\circ} \mathrm{C}$. The PET fibres were (partially) melted and pressed during the process to make a thin $(0.5 \mathrm{~mm}$ thickness) carbon fibre/PET tape (Figure 1d). For this work, the wider tape was then slit into a narrow width (20mm) (Fig. 1e) to be used in fabric structures.

\subsection{Composite fabrication}

Two types of composite samples were fabricated by placing the tapes into two different tape architectures in 0/90 layup. The first sample was fabricated from the tape cross plies and the second sample was fabricated from the tape woven plies (Figure 1f), respectively. The tape woven plies ( $1 \times 1$ plain weave) were made by hand. In both cases, five layers of plies were hot-pressed at $285^{\circ} \mathrm{C}$ for 20 minutes under 30 bar pressure to make $2.0 \mathrm{~mm}$ thick panels.

\subsection{Physical and mechanical testing of composite panels}

The fibre volume fraction was determined by chemical digestion method, as per ASTM D3171. The tensile properties were tested in the $0^{\circ}$ direction according to ASTM D3039M-14 and flexural tests were carried out according to ASTM D7264M-07. Compressive strength of the laminates was measured according to ASTM D695-89. For impact tests, a drop weight impact test (Instron east 9350 model) on the samples (90mm x $55 \mathrm{~mm}$ x $2 \mathrm{~mm}$ ) was carried 
out following a previously developed method [15] at three energy levels (5, 10 and $15 \mathrm{~J}$ ), using a modified clamping rig for thin ( 2 mm thickness) composites. The test coupon was clamped between plates with $40 \mathrm{~mm}$ diameter hole in the middle of the plate and the rig was equipped with a device to ensure that multi-impacts were eliminated. The head diameter of the impactor was $20 \mathrm{~mm}$ and speed was $5 \mathrm{~m} / \mathrm{s}$. An ultrasonic inspection machine (C-Scan Midas-NDT) was used for the scanning the damaged area. Carbon fibre distribution in the matrix and fracture parts of the tested specimens were examined using an optical microscope (Olympus BX41) and the cross-sections of the specimens were viewed under a scanning electron microscope (SEM).

\section{Results and discussions}

The measured physical and mechanical properties of the waste carbon fibres, PET fibres and neat PET plaque are presented in Table 1. The carbon fibres used in this experiment had tensile strength of $3190 \mathrm{MPa}$ and modulus of $242 \mathrm{GPa}$. The PET fibres had a melting point of $248{ }^{\circ} \mathrm{C}$, crystallinity of $38.5 \%$, breaking load of $0.23 \mathrm{~N}$ (357 MPa) and extension to break of $10 \mathrm{~mm}$. The tensile strength and modulus of unfilled PET matrix plaque were found to be 47 $\mathrm{MPa}$ and $3.5 \mathrm{GPa}$, and the flexural strength and modulus were found to be $118 \mathrm{MPa}$ and 4.0 GPa, respectively.

Semi-consolidated tape was produced from the slivers of carbon fibre/PET fibre because the slivers were weak (breaking strength of ca. $1 \mathrm{~N}$; see Figure 3a) to handle in further processes. During the tape making process, the PET fibres were partly melted by heating and pressing the slivers at near the melting temperature of PET. The breaking strength of the tape was increased to 370N (see Figure 3b), which was sufficient for handling in the tape slitting process to produce narrow tapes and in producing the fabric architectures. 
During composite fabrication, the tape plies were heated at a high temperature $\left(280{ }^{\circ} \mathrm{C}\right)$, which was higher than the melting temperature of PET, and under high pressure (30 bar). PET fibres were fully melted and consolidated in the moulded composites. SEM images of panel cross-sections (Figure 4) clearly show that while many regions of the composite are well-consolidated, there are some dry regions where the carbon fibres were not properly bonded with the matrix. The presence of voids (15-17\%) was also indicated by the large range in density $\left(1.45 \mathrm{~g} / \mathrm{cm}^{3}\right.$ and $\left.1.52 \mathrm{~g} / \mathrm{cm}^{3}\right)$ between samples. Acid digestion tests revealed that overall the carbon fibre was fairly evenly distributed in the panel, with fibre volume fraction ranging between 50 to 56\% (Table 1). However, Figure 5 shows that the carbon fibre and PET blend ratios in different zones of a SEM micrograph of a sliver varies from $40 \%$ to $60 \%$, suggesting that while overall variability in fibre distribution is not substantial, local variability is. This volumetric variation in the composite samples was likely due to uneven blending of carbon fibres with PET fibres in the tape, perforce of the uneven blending of the two fibres at sliver production stage. It is conceivable that local regions of tape at the lower range of fibre volume fraction wetted out better during hot-compaction, whereas poor consolidation and voids appeared in regions with higher fibre volume fraction.

Two types of composite panels were fabricated from the tapes. The mechanical tests on the composites were conducted in $0^{\circ}$ direction of 0/90 layup. A summary of results obtained from both tensile and flexural testing is presented in Table 2. The mean maximum tensile stress values for the cross-ply and woven ply laminates were very comparable at $295 \mathrm{MPa}$ and 300 MPa, respectively. The tensile moduli were also found to be similar at $26.5 \mathrm{GPa}$ and 25.5 GPa, respectively. Observations of tensile fractured specimens revealed that delamination occurred at mid-thickness of all cross-ply samples. On the other hand, all woven ply test specimens failed at the interlacement points of the weave structure. While tensile properties of the woven and cross-ply composites were similar, flexural properties were significantly 
different. The flexural strengths were found to be $172 \mathrm{MPa}$ and $83 \mathrm{MPa}$ for cross-ply and woven ply composites, respectively. The bending modulus was also higher for cross-ply composites compared to woven ply composites. No delamination was found in cross-ply laminates, but for woven ply composites, clear failure cracks were visible in the tape interlacement areas of bend-tested specimens, possibly explaining the lower bending properties.

Under compressive loading, all cross-ply samples failed near the top loading plate and visual inspection showed that ply-cracking and delamination occurred in the failure area. The mean compressive strength was found to be $77 \mathrm{MPa}$ (Table 2). On the other hand, for woven ply composites the mean stress was found to be lower at 44 MPa (Table 2). Stress-strain profiles for woven ply composites showed distinct load-drops, indicating multiple ply-cracking. Inspection of failed specimens revealed that all weave structures failed at the warp and weft interlacement in the composite. The mean compressive strain at maximum stress was higher for woven ply composites (at $0.43 \%$, compared to $0.3 \%$ for cross-ply composites).

The behaviour of the materials under impact load was also investigated. Figures 6a-c and Figure 6d-f show the different damage behaviour of cross-ply and woven ply laminates, respectively under $5 \mathrm{~J}, 10 \mathrm{~J}$ and $15 \mathrm{~J}$ work of impact forces, respectively. The damage areas of the specimens were scanned and calculated for all samples and presented in Figure 7. It was seen that the average damage force was $2600 \mathrm{~N}$ under the $5 \mathrm{~J}$ impact energy level. But this value reached to $3230 \mathrm{~N}$ under $10 \mathrm{~J}$ impact energy level. No penetration was observed for the samples tested under $5 \mathrm{~J}$ and $10 \mathrm{~J}$, except delamination. At $15 \mathrm{~J}$, the damage force increased further to $3900 \mathrm{~N}$, yet no penetration seen in this case either. Only one of the samples was penetrated by the impactor, while the others exhibited delamination of layers and visibly higher plastic deformation on the impact face. No penetration of ply layers was occurred. On the other hand, the average damage forces for woven ply composites under the 
same impact energy levels were found to be higher (2670 N, $3500 \mathrm{~N}$, , $4300 \mathrm{~N}$, respectively) compared to cross-ply laminates. No penetration was observed at $5 \mathrm{~J}$ impact energy but at 10 $\mathrm{J}$ energy impactor penetration and delamination of the layers was observed for woven ply samples. In comparison to woven ply composites, cross ply composites showed lower damaged area under $15 \mathrm{~J}$ (average value:130 $\mathrm{mm}^{2}$ ), which was nearly same damaged area for $5 \mathrm{~J}\left(135 \mathrm{~mm}^{2}\right)$, but slightly larger damaged area was seen under $10 \mathrm{~J}$ force $\left(150 \mathrm{~mm}^{2}\right.$ ) (Figure 7). It was also seen that the damage was mainly constrained at the area of impactor and some of the specimens show delamination of the back face, where the fibre spalling occurred and the samples could withstand higher energy forces than $15 \mathrm{~J}$ till complete penetration. No inter-ply delamination was seen in this case, which was due to non-woven ply architecture that allows better fibre flaws between 0/90 directions.

For the woven ply structure, the damage under $15 \mathrm{~J}$ was much higher $\left(230 \mathrm{~mm}^{2}\right)$ although lower damage areas were seen for $5 \mathrm{~J}$ and $10 \mathrm{~J}$ impact energy levels but higher penetration and permanent indentation was clearly visible in both cases. It was seen that the laminates broke in the weak area at the interlacements and there appeared to be some intra-ply damage along warp and weft directions in addition to the large area of inter-ply delamination (see Figure 8).

The results can also be compared with virgin carbon fibre/LPET (LPET-modified amorphous PET matrix) commingled yarn fabric (0/90) composites (comfil ${ }^{\circledR}$ thermoplastic composites: http://www.comfil.biz) as no other carbon fibre/PET thermoplastic prepreg materials are commercially available. It is reported that the tensile strength and modulus of virgin and continuous carbon fibre/PET (50/50 wt.\%) were 445.0 MPa and 38.0 GPa, respectively. The tensile properties (strength and stiffness) for recycled carbon fibre/PET tape composites are $30 \%$ lower than continuous carbon fibre/LPET composites. Both the properties can be further enhanced for recycled carbon fibre/PET tape composites by increasing the PET resin content 
in the tape, as it is evident that insufficient matrix led to substantial voidage in the tape laminate composites.

\section{Conclusion}

A novel thermoplastic tape from 60 wt.\% waste carbon fibres and 40 wt.\% PET fibres has been developed as a dry prepreg semi-product. Cross-ply and woven ply composites were thereafter fabricated by hot-pressing the tape materials. Mechanical tests revealed that while the cross-ply and woven ply composites performed comparably in tensile mode, the flexural, compressive, and impact behaviour of cross-ply composites was superior to the woven ply material. Particularly, the warp and weft tape interlacements in the woven tape composite structure played an important role in the fracture of the material, initiating delamination (e.g. ply cracking under both tensile and flexural loading) and therefore leading to comparatively lower mechanical properties. Microscopic evidence revealed that local variation in fibre distribution may have induced dry spots and voidage; optimising the manufacturing process needs further study. This initial work has shown that short, waste carbon fibres may find high-value uses in thermoplastic tape composite materials, offering the ability for rapid production and useful mechanical properties.

\section{Acknowledgements}

The authors would like to thank Tilsatec Advanced Textile Materials and School of Materials, University of Manchester to support this study project.

\section{References:}

1. Soria, P. Silvertre, T. Recycling carbon fibres reinforced polymers for structural applications: Technology and market outlook. Waste Mang. 2011; 31(2): 378-392.

2. Davidson J. Carbon Fibre Composites: Advancements in reclamation processes and recycled material forms. Composites Innovation 2007 Conference Proceedings, 
Barcelona, Spain, October 4-5, 2007.

3. Roberts, T. The carbon fibre industry worldwide 2011-2020. Materials Technology Publications, Watford, UK.

4. Akonda $\mathrm{MH}$, Lawrence $\mathrm{CA}$ and Weager B. Recycled carbon fibre reinforced thermoplastic polypropylene composites. Comp. Part A; Apli. Science and Manu., 2012; 43 (1): 79-86.

5. Akonda $\mathrm{MH}$, Lawrence CA and Weager B. FibreCycle project review and key findings. 15Th Annual Global Outlook for Carbon Fibre, London, UK, October 2-4, 2011.

6. H. M. El-Dessouky, C.A. Lawrence. Ultra-lightweight carbon fibre/thermoplastic composite material using spread tow technology. Comp. Part B, 2013; 50:91-97.

7. Van Rijswijk, K. and Bersee, H.E.N. Reactive processing of textile fibre-reinforced thermoplastic composite - an overview. Composites: Part A, 2007; 38:666-681.

8. Chang IY, Lees JK. Recent Development in thermoplastic composites: a review of matrix systems and processing methods. Journal of Thermoplastic Composite Materials 1988; 1 : 277-296.

9. Yang, Y., Boom, R., Irion, B., van Heerden, D., Kuiper, P., and deWit, H. Recycling of composite materials. Chemical Engineering and Processing, 2012; 51:53-68.

10. Mitschang P, Blinzler M, Woginger A. Processing technologies for continuous fibre reinforced thermoplastics with novel polymer blends. Compos Sci Technol 2003; 63:2099-110.

11. Goodman KE, Loos AC. Thermoplastic prepreg manufacture. J Thermoplast. Compos Mater 1990; 3:34-40.

12. Keuchel KH. Method of delivering a thermoplastic and/or crosslinking resin to a composite laminate structure. US P 0309260A1, December 17; 2009.

13. Fujihara, K., Zheng-Ming, H., Ramakrishna, S., and Hamada, H. Influence of processing conditions on bending property of continuous carbon fiber reinforced PEEK composites. Composite Science and Technology, 2004; 64:2525-2534.

14. Pickering, S., Recycling technologies for thermoset composite materials - current status.

Composites Part A: Applied Science and Manufacturing, 2006; 37: 1206-1215.

15. Prichard, J.C. and Hogg, P.J. The role of impact damage in post-impact compression testing. Composites, 1990; 21(6):503-511. 


\section{Tables and Figures:}

Table 1. Measured physical and mechanical properties of carbon fibre, PET fibre and unfilled PET plaque. Values indicate mean \pm one standard deviation

\begin{tabular}{|l|c|c|c|}
\hline Properties & Carbon fibre & PET fibres & PET resin plaque \\
\hline Fibre length $(\mathrm{mm})$ & $60.0 \pm 3.0$ & $60.0 \pm 0.5$ & - \\
\hline Fibre diameter $(\mu \mathrm{m})$ & $7.60 \pm 0.01$ & $28.0 \pm 0.02$ & - \\
\hline Linear density (dtex) & $0.75 \pm 0.07$ & $7.6 \pm 0.3$ & $47 \pm 2$ \\
\hline Tensile strength $(\mathrm{MPa})$ & $3190 \pm 56$ & - & $3.5 \pm 0.5$ \\
\hline Tensile modulus $(\mathrm{GPa})$ & $242.0 \pm 5.4$ & - & $418 \pm 2$ \\
\hline Flexural strength, MPa & - & - & $1.5 \pm 0.5$ \\
\hline Flexural modulus, GPa & - & - & - \\
\hline Strain to failure $(\%)$ & $1.10 \pm 0.22$ & - & - \\
\hline Crystallinity $(\%)$ & - & 38.5 & - \\
\hline Melting point $\left({ }^{\circ} \mathrm{C}\right)$ & - & 248 & 10.0 \\
\hline Extension at break $(\mathrm{mm})$ & - & & \\
\hline
\end{tabular}

Table 2. Summary of tensile, flexural and compression test results of fabricated composites.

Values indicate mean \pm one standard deviation

\begin{tabular}{|c|c|c|c|c|c|c|}
\hline $\begin{array}{l}\text { Specimen } \\
\text { type }\end{array}$ & $\begin{array}{l}\text { Fibre } \\
\text { volume } \\
\text { fraction } \\
\text { (\%) }\end{array}$ & $\begin{array}{l}\text { Tensile } \\
\text { modulus } \\
\text { (GPa) }\end{array}$ & $\begin{array}{l}\text { Tensile } \\
\text { strength } \\
\text { (MPa) }\end{array}$ & $\begin{array}{l}\text { Flexural } \\
\text { modulus } \\
(\mathrm{GPa})\end{array}$ & $\begin{array}{l}\text { Flexural } \\
\text { strength } \\
(\mathrm{MPa})\end{array}$ & $\begin{array}{l}\text { Compressive } \\
\text { stress at } \\
\text { maximum } \\
\text { load } \\
(\mathrm{MPa})\end{array}$ \\
\hline Cross-ply & 53.0 & $26.5 \pm 2.2$ & $295 \pm 25$ & $25.4 \pm 2.2$ & $172 \pm 20$ & $77 \pm 12$ \\
\hline Woven ply & 53.0 & $25.5 \pm 3.3$ & $300 \pm 20$ & $21.3 \pm 5.0$ & $83 \pm 22$ & $43 \pm 11$ \\
\hline
\end{tabular}



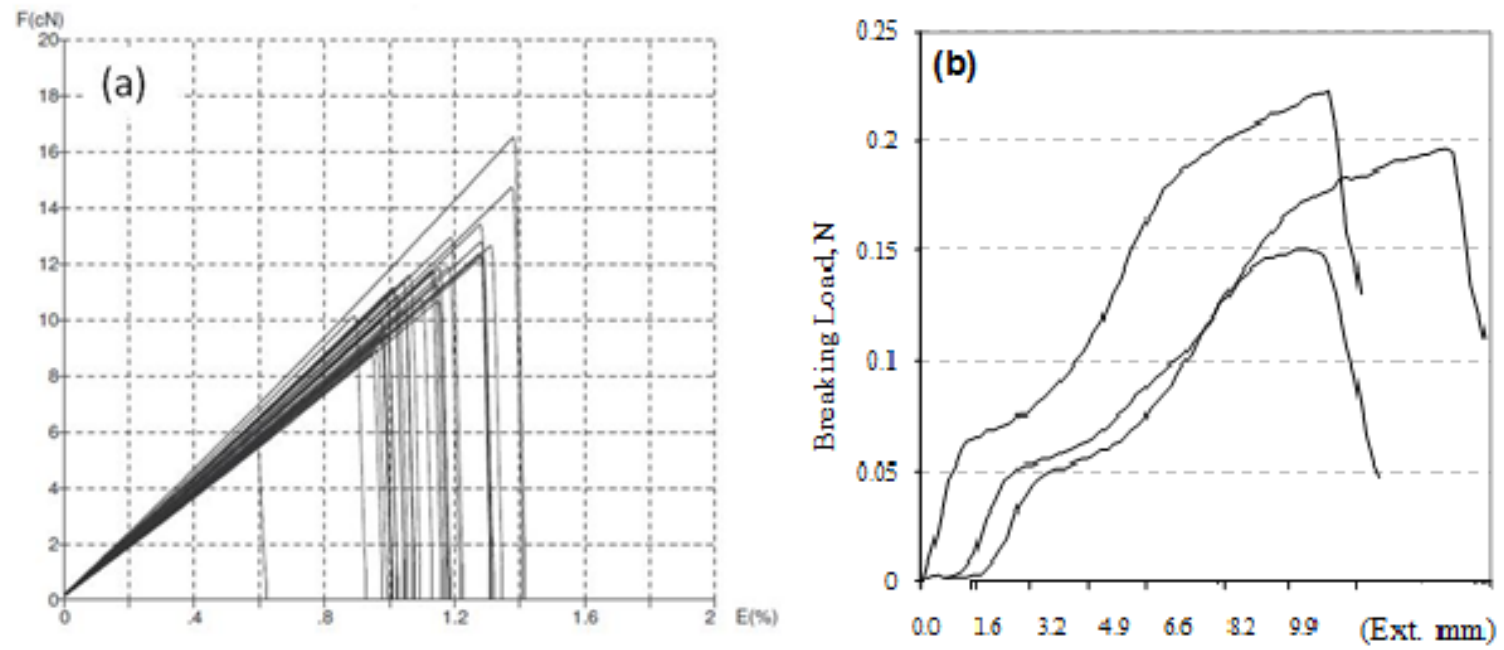

Figure 1. Load-elongation curves of (a) waste carbon fibres and (b) polyester (PET) matrix fibres

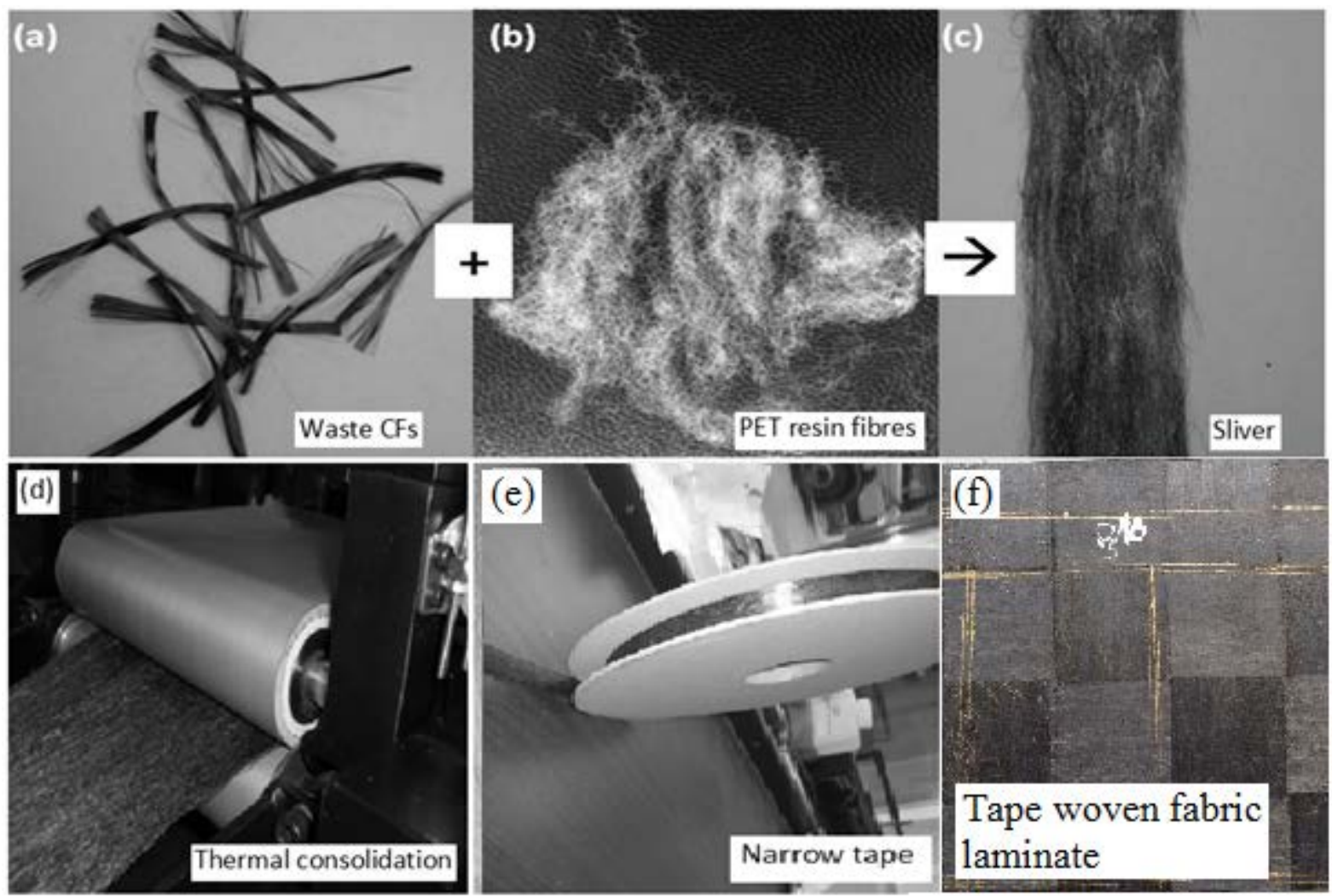

Figure 2. (a-d) Tape production process from slivers of waste carbon and PET fibres, (e) narrow tape and (f) composite panel made from tape woven fabric 

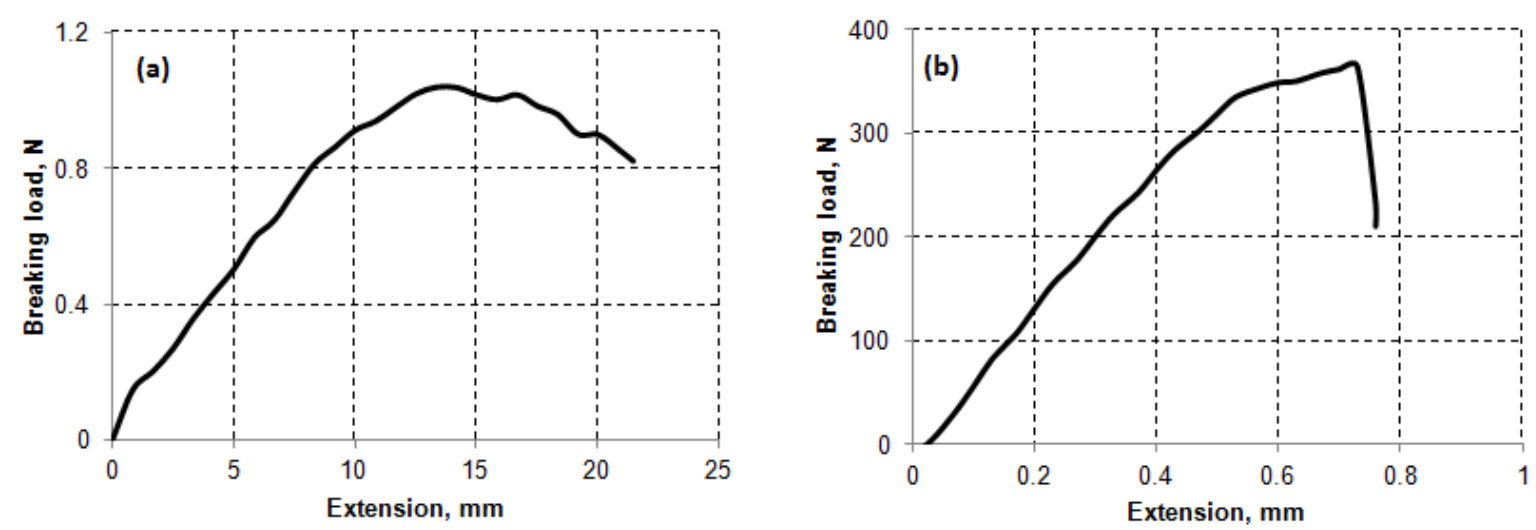

Figure 3. Load-extension curves of (a) carbon fibre/PET sliver (pictured on Figure 2c), and (b) semi-consolidated carbon fibre/PET tape (pictured in Figure 2e).
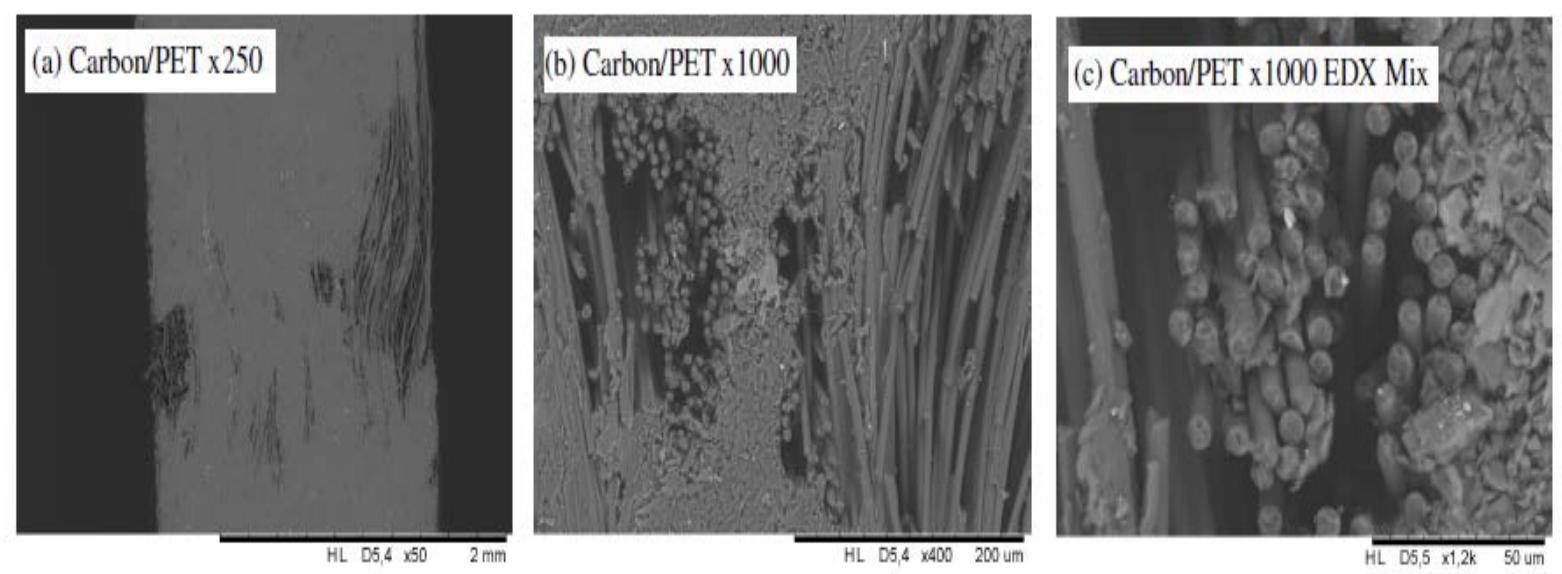

Figure 4. SEM images showing dry carbon fibres in the composites due to insufficient matrix 

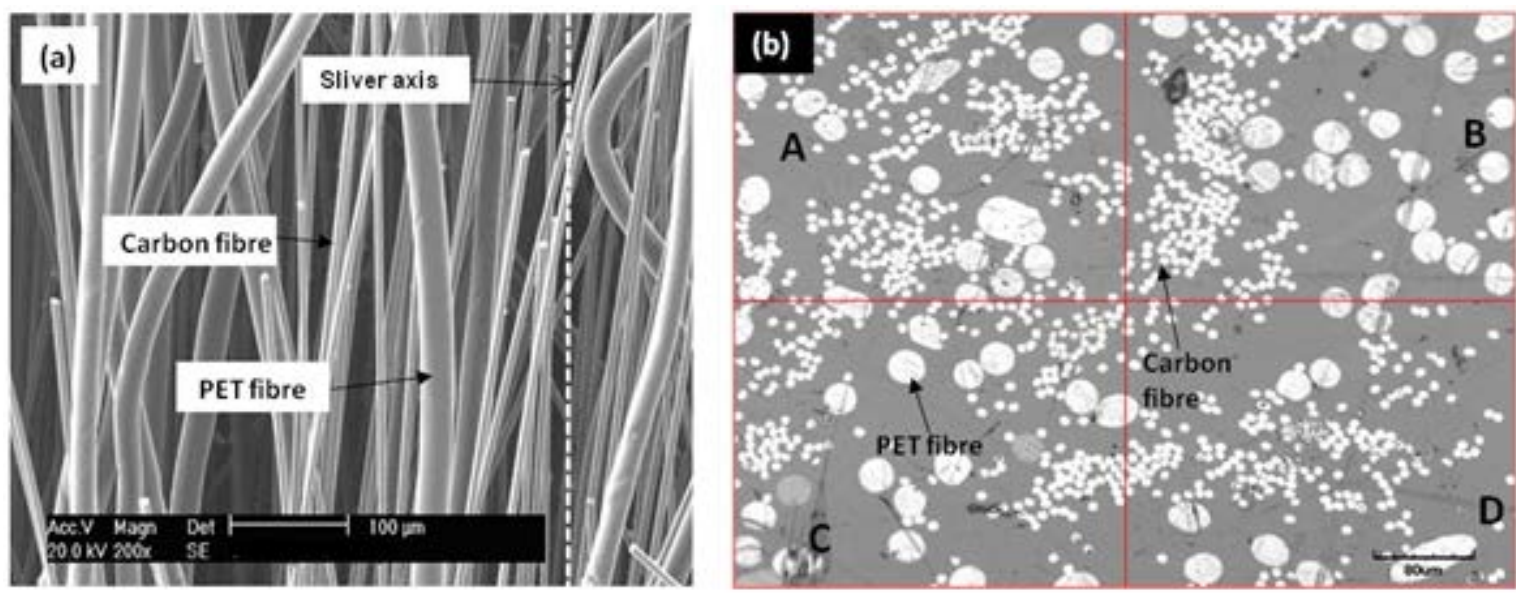

Figure 5. (a) SEM images of carbon fibre/PET blends in the sliver, (b) optical cross section of the sliver. Image analysis of the four quadrants revealed the variation in carbon fibre to PET volumetric percentage ratio: A 55.7\% carbon fibre : 44.3\% PET fibres, B 47.3:52.7, C 41.8:58.2, and D 59.0:41.0.

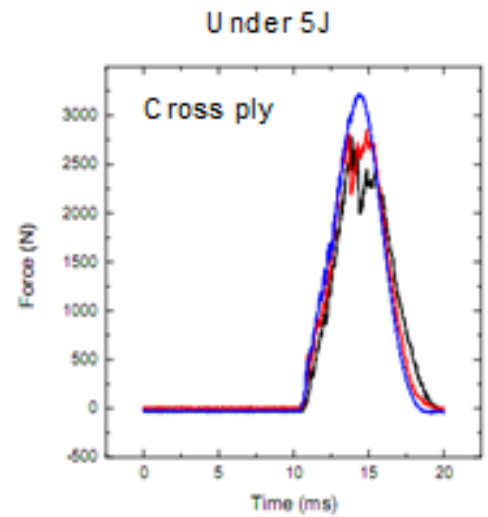

(a)

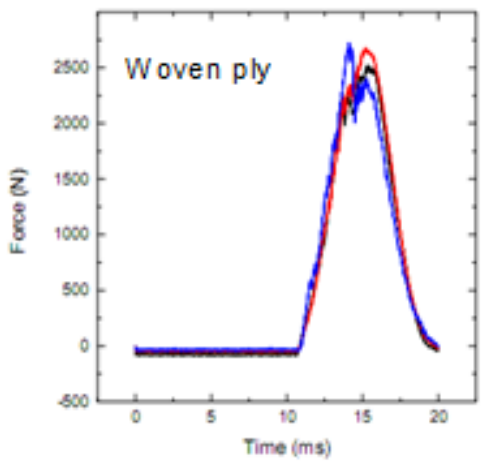

(d)

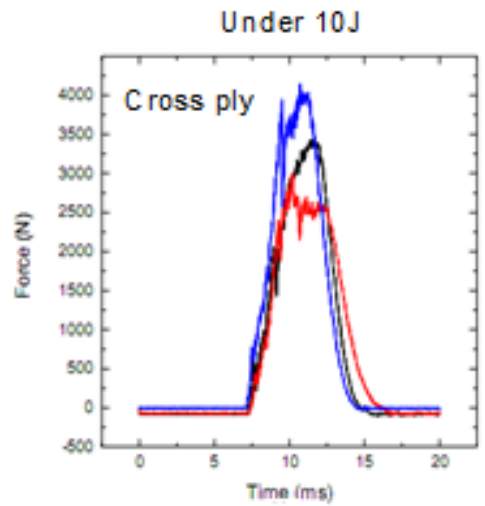

(b)

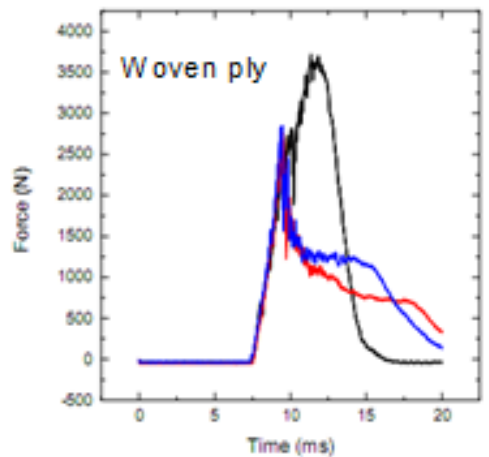

(e)

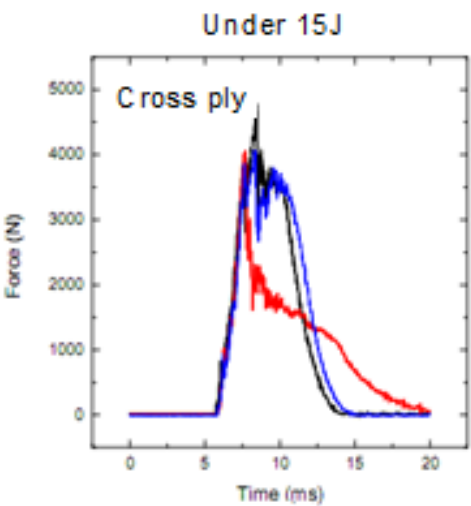

(c)

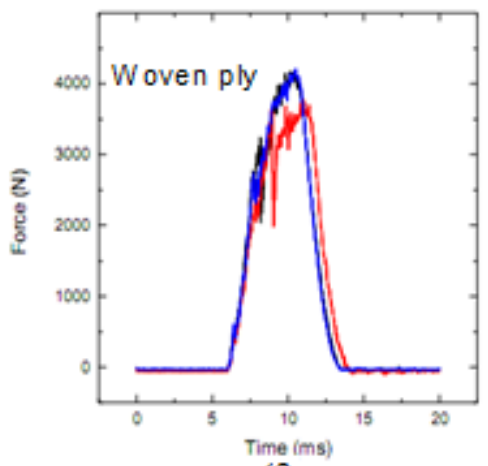

(f)

Figure 6. Temporal evolution of damage forces (a-c) for cross-ply and (d-f) for woven ply laminates under 5, 10 and 15J energy levels. 


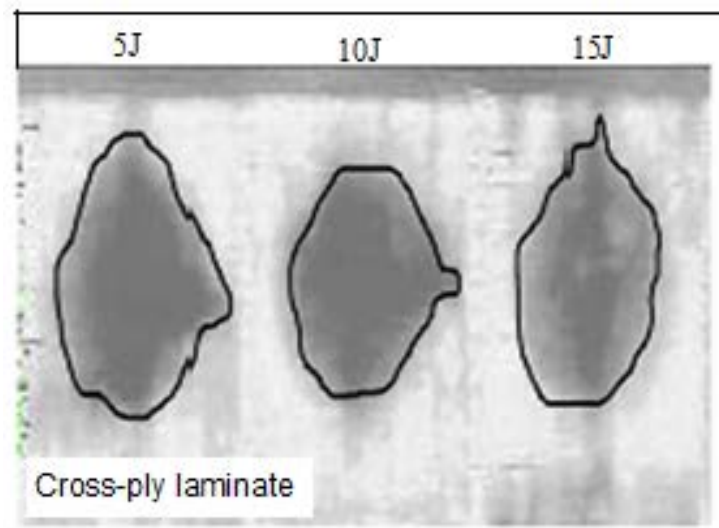

$155.18 \mathrm{~mm}^{2} 128.04 \mathrm{~mm}^{2} 131.41 \mathrm{~mm}^{2}$

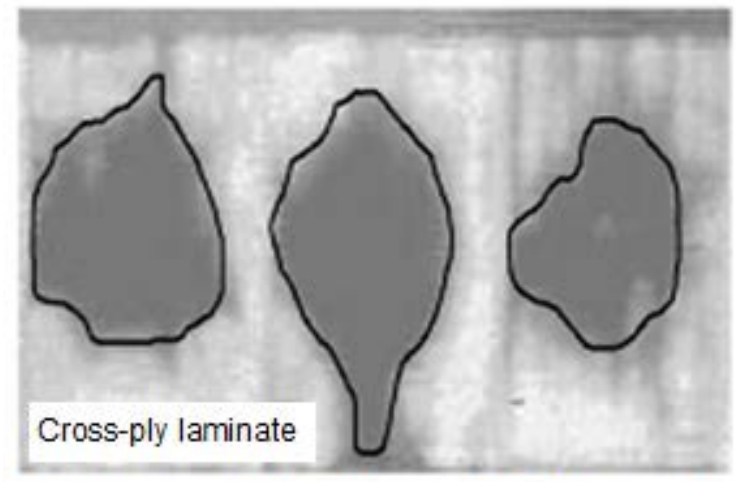

$168.05 \mathrm{~mm}^{2} 180.18 \mathrm{~mm}^{2} 123.69 \mathrm{~mm}^{2}$

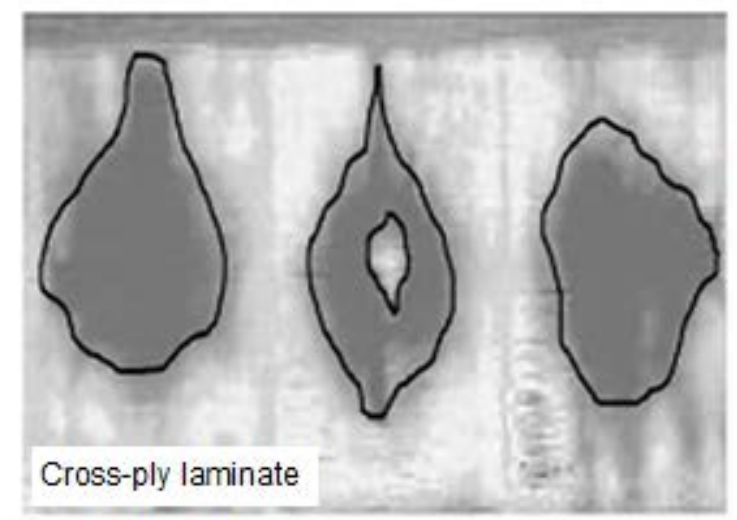

$155.67 \mathrm{~mm}^{2} 118.04 \mathrm{~mm}^{2} \quad 144.3 \mathrm{~mm}^{2}$
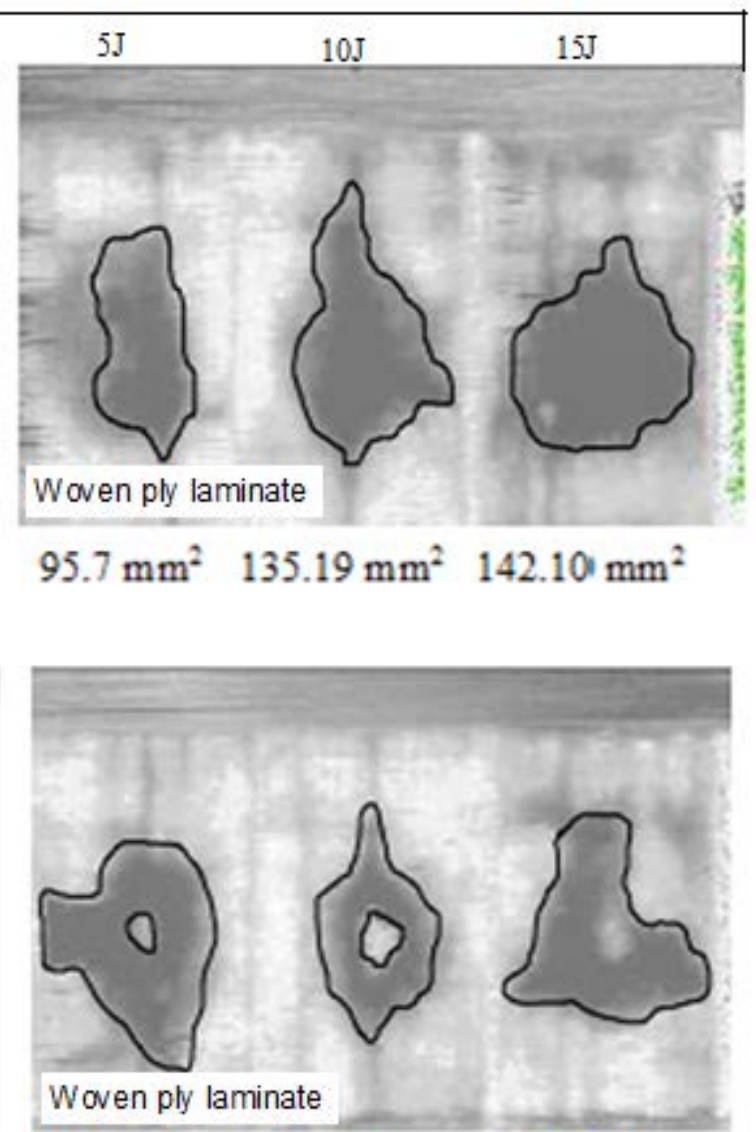

$162.01 \mathrm{~mm}^{2} \quad 109.57 \mathrm{~mm}^{2} \quad 148.71 \mathrm{~mm}^{2}$

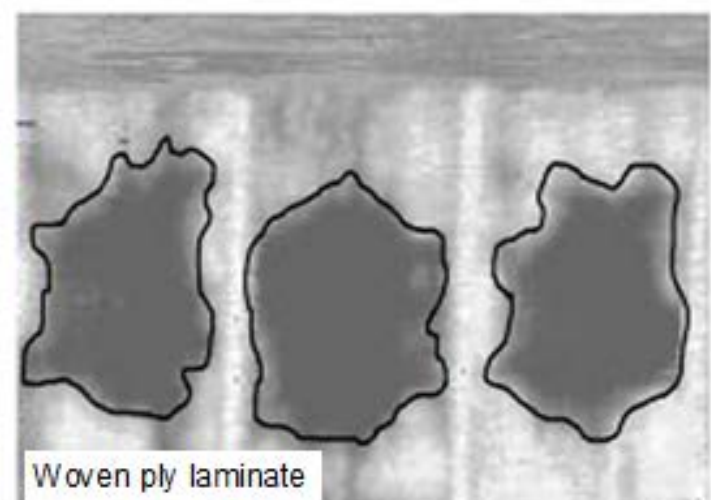

$213.84 \mathrm{~mm}^{2} \quad 234.41 \mathrm{~mm}^{2} 231.44 \mathrm{~mm}^{2}$

Figure 7. Calculated damage areas of the samples tested under 5J, 10J and 15J impact energy level impact (in Figure 6). Samples with penetration of impactor are identifiable by the presence of a lighter grey lumen in the centre of the damage areas 


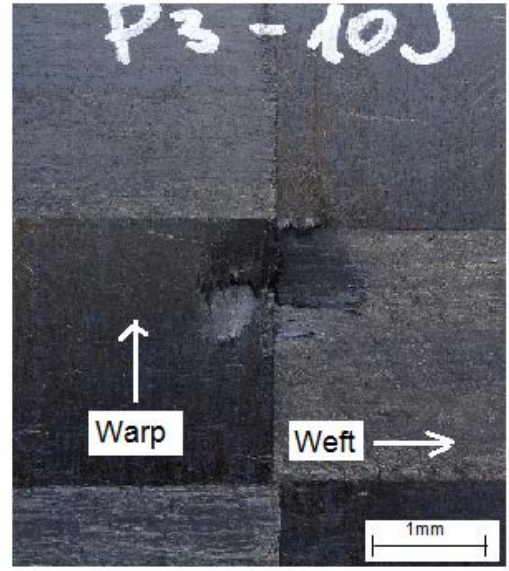

Impacted sample front face

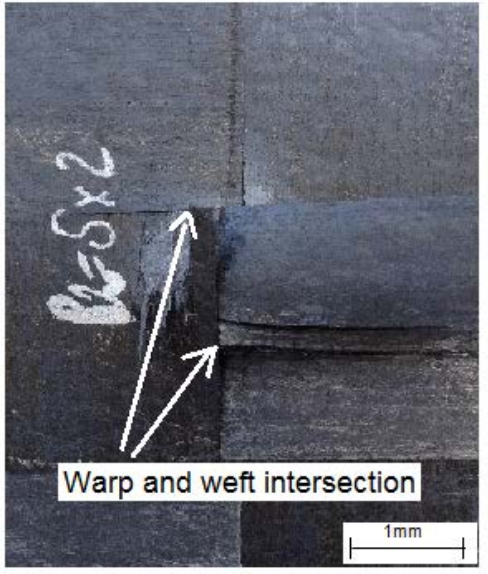

Impacted sample back face

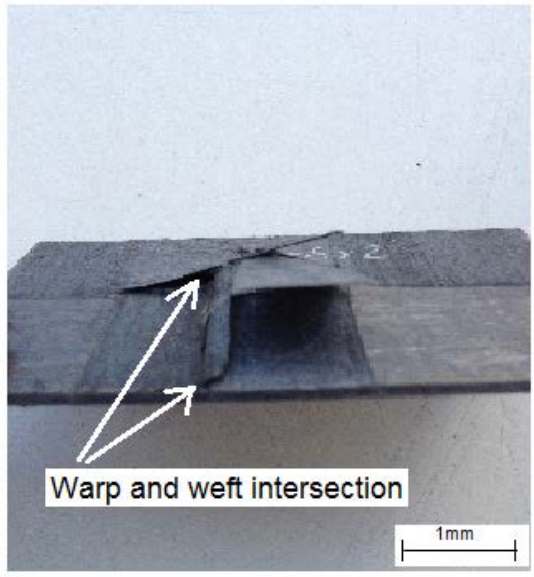

Impacted sample side view

Figure 8. Inter ply delamination of woven tape composites under impact test (10J impact energy) 